\title{
Research on Satisfaction Evaluation Based on Tourist Big Data
}

\author{
Hanwen Guo ${ }^{1}$, Ziyang $\mathrm{Liu}^{2 *}$, and Zeyu $\mathrm{Jiao}^{2}$ \\ ${ }^{1}$ Business School, GuangXi University for Nationalities, GuangXi, China. \\ 11757749499@qq.com. \\ 2*, 2 Department of Global business, University of Kyonggi Suwon, Korea \\ 2*morninglzy@hotmail.com, 2447052870@qq.com \\ *Corresponding author: Ziyang Liu
}

Received September 25, 2021; revised December 6, 2021; accepted August 11, 2021; published January 31, 2022

\begin{abstract}
With the improvement of people's living standards and the development of tourism, tourists have greater freedom in choosing destinations. Therefore, as an indicator of satisfaction with scenic spots, tourist comments are becoming increasingly prominent. This paper aims to compare and analyze the landscape image of the Five Great Mountains in China and provide specific strategies for its development. The online reviews of tourists on the Online Travel Agency (OTA) website about the Five Great Mountains from 2015 to 2018 are collected as research samples. The text analysis method and $\mathrm{R}$ language are used to analyze the content of the tourist reviews, while the high-frequency words in the word cloud are used for visual display. In addition, the entropy weight method is used to determine the index weight and tourist satisfaction is evaluated to understand the weaknesses of those scenic spots. The results of the study show that firstly, the tourist satisfaction with the Five Great Mountains is basically consistent with its popularity. Secondly, through weight analysis, tourists pay special attention to the landscape features and environmental health of the scenic area, so that relevant departments should focus on building the landscape characteristics and improving the environmental health of the scenic area. At the same time, the accommodation and service management of the scenic spot cannot be ignored. Finally, according to the analysis results, suggestions are made on how to improve the tourist satisfaction with the Five Great Mountains.
\end{abstract}

Keywords: Online Travel Agency, Text Analysis, Word Cloud, The Five Great Mountains, Tourist Satisfaction 


\section{Introduction}

In recent years, China's tourism informatization construction has achieved considerable development. With the tourism online service market gaining scale, the marketing pattern with full-coverage tourism propaganda has basically formed. Meanwhile, tourism e-government has been steadily advancing and tourism informatization has significantly strengthened the tourism industry [1]. Under the background that the combination of information technology and tourism turned into a new development hotspot, the smart tourism service system has become one of the focus of enterprise construction [2]. According to the China Scenic Tourism Research Report, at least $81.5 \%$ of tourists often share their travel experiences on WeChat, Weibo, OTA (Online Travel Agency), community forums, etc. and $84.8 \%$ of tourists share travel experiences instantly through social tools. Among tourists who often share travel experiences, $60.4 \%$ of them refer to the travel guide and arrange their travel itinerary according to the guide. As online travel has dominated China 's tourism market, various OTA sites make an effort to take a slice of this market. In this condition, tourists use these OTA sites to evaluate the experience of scenic spots, especially after the $4 \mathrm{G}$ era spreading across different provinces in China. To a great extent, real-time reviews of scenic spots and the follow-up reviews both reflect the tourists' image perception and satisfaction about the scenic spot. In recent years, a large number of scholars have used online reviews to study customer satisfaction. Radojevic and other scholars have statistically analyzed the text data of hotel reviews and found that tourists are more concerned about the star rating, room layout and air conditioning equipment when they stay at the hotel [3]. Scholar Zhao analyzed tourist satisfaction with scenic spots in world cultural heritage sites such as the ancient city of Pingyao and Yungang Grottoes by using online reviews as a sample [4]. Through online data, Li took the key scenic spots in Xi'an as an example to construct a tourist satisfaction model and analyzed the tourists' satisfaction with the scenic spots in Xi'an [5]. From the previous research, there are more and more scholars who use network text data as a method of satisfaction research.

American scholar Cardozo first introduced the concept of "satisfaction" in marketing in 1965 to show that customer satisfaction will drive customer behavior [6]. After 1970, Pizam and other scholars applied the concept of satisfaction to the tourism industry, which provided a theoretical basis for future scholars to study tourist sites and tourist satisfaction [7]. Chinese scholars' research on tourists and satisfaction began in the late 1980s. Since the development of the tourism market should focus on tourists, many scholars put effort on investigating the way of improving tourists' satisfaction with scenic spots. The research on tourist satisfaction in this paper mainly uses the definition put forward by Pizam and other scholars, which shows that tourist satisfaction is the comparison result of tourists 'expectations and actual experience. If the travel destination almost meets the tourists' expectations, it indicates that the tourists are satisfied. Otherwise, it means tourists are not satisfied [8].

The Five Great Mountains in China has always been a popular scenic spot for tourists. The Five Great Mountains in China has always been a popular scenic spot for tourists. Under the background of tourism market demand and from the perspective of cultural consciousness, Guoxia Zhang analyzes the current situation of overseas communication of Mount Tai culture and puts forward some suggestions on communication strategies accordingly [9]. Taking Baiyun Mountain and Mountain Hua as examples, Yan Cui studied the tourist satisfaction of mountain-type scenic spots, and put forward suggestions for different indicators affecting the tourist satisfaction [10]. Therefore, scholars in China have never stopped doing research on this famous attraction. The research content mainly includes tourist satisfaction with scenic spots, protection of scenic spot resources and tourism development, as well as cultural aspects 
of scenic spots. Most scholars use the method of qualitative research and some scholars conduct research in quantitative terms. However, quantitative analysis mostly focuses on the tourist and relatively few studies focus on scenic spots [11] [12]. Based on the perspective of tourists, this article compares and analyzes the satisfaction of tourists in the five scenic spots of the Mount Hua in Shaanxi, the Mount Thai in Shandong, the Mount Song in Henan, the Mount Heng in Hunan and the Mount Heng in Shanxi. In the context of big data, it researches the needs of tourists based on the word-of-mouth from the third-party Internet. By monitoring OTA tourist reviews through the entire network, network reviews and public opinion data are deeply mined and data evaluation models are built to understand tourists' needs and emotional changes in a more scientific and intelligent way. And this study will contribute to a more scientific and intelligent understanding of the changes in the needs and emotions of tourists in the five scenic spots, find out the shortcomings of the development of the five scenic spots, and provide reference for the follow-up development and management decisions of the scenic spots [13] [14].

\section{Research Method}

\subsection{Data Sources}

The research data of this paper is mainly taken from the evaluation text of the scenic spots provided by the tourists who used the three platforms of Ctrip, Meituan and Qunar to buy tickets of the Five Great Mountains between 2015 and 2018. The paper uses Python software for data crawling and the text data was published from January 1, 2015 to December 31, 2018. The total amount of data initially obtained was 81254. Among the data, the number of data from the Mount Thai and the Mount Hua is 17641 and 17515 respectively, while the data number from the Mount Heng in Hunan is 15321 and the Mount Heng in Shanxi is 14229. The amount of data from the Mount Song is 16848. Then the data was selected by removing duplicate data and default praise. The principle of comment elimination is to clean reviews of irrelevant subject content, repeated reviews, reviews that are too radical or highly commercial and reviews that are irrelevant to visitor satisfaction, etc. Ultimately, the initial data for controlling subsequent calculation of satisfaction with the Five Great Mountains are all eliminated to 12,000, with a total data volume of 60,000. Compared with traditional methods such as questionnaire surveys, the advantages of the network text analysis method include the large sample size, rich content and fast acquisition speed. As a result, the text content is timesensitive and more authentic. Whereas, there are some disadvantages including the narrow age range of the sample group and the inability to set subjective questions to investigate tourist satisfaction [15].

\subsection{Research process}

Based on the review sample, this paper mainly adopts the text analysis method according to the steps of sample data collection $\rightarrow$ word frequency statistics $\rightarrow$ project construction $\rightarrow$ satisfaction calculation $\rightarrow$ result analysis. The Python is firstly used to collect the review samples of the Five Great Mountains separately, then the invalid content of data is removed after the collection [16]. On the basis of data removal rules mentioned above, the data is imported into the R language software to use the word cloud package to perform text word frequency statistics (Table 1). In the final, the word cloud is generated for visual presentation (Fig. 1). 


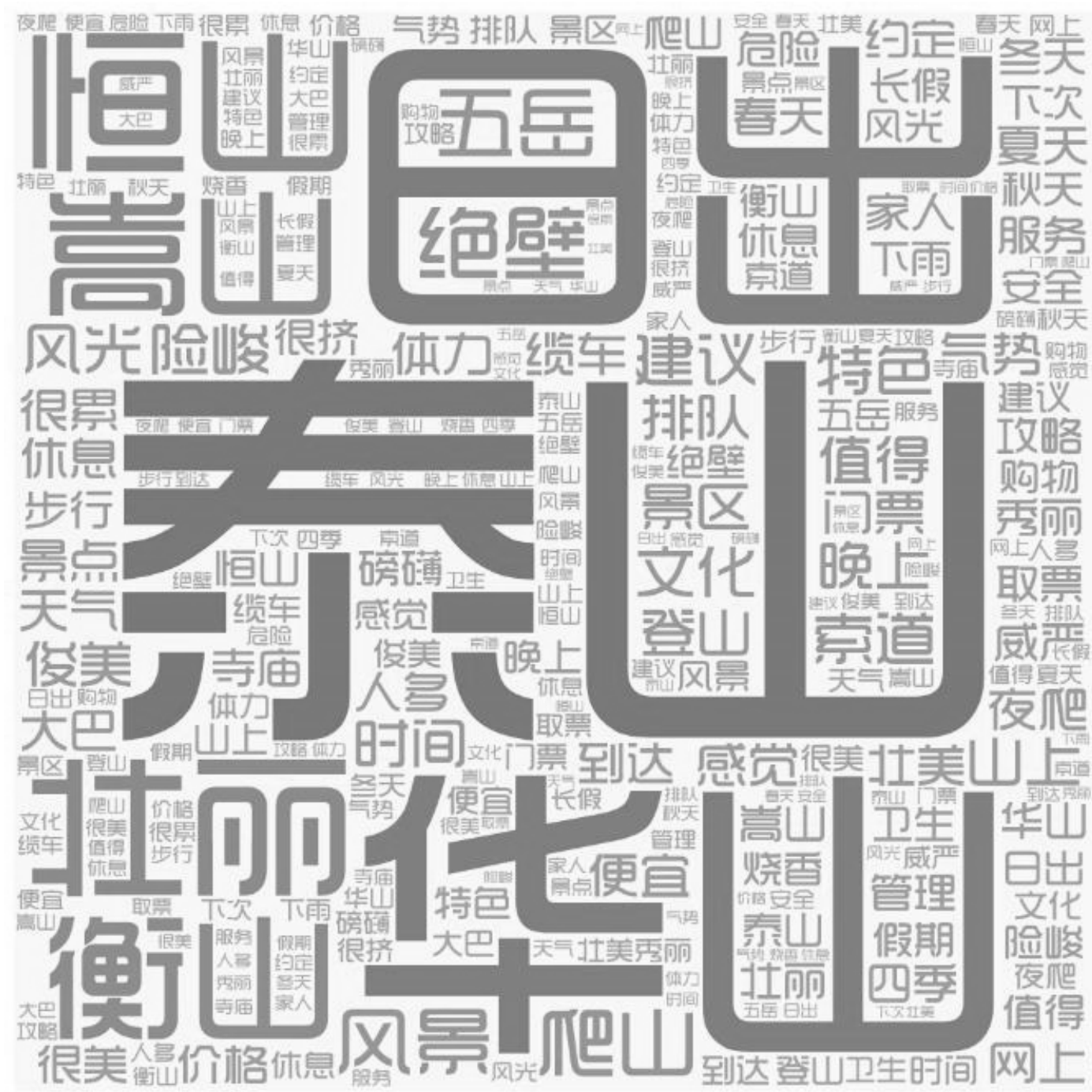

Fig. 1. High-frequency word cloud of the Five Great Mountains

landscape features, cultural characteristics, infrastructure and service management. According to the elimination criteria above, the remaining texts are all related to tourist satisfaction and emotional expressions. The text contained in the nine classified indicators is imported into $\mathrm{R}$ language and sentiment analysis is performed. The sentiment classification is divided into 3 comments, which are positive comments, neutral comments and negative comments. In this paper, the fuzzy comprehensive evaluation method and the normalization method are used to process the sentences of the sentiment classification. The weights of the three reviews are 1, 0.5, and 0.1. After calculation, the initial data of tourist satisfaction in the Five Great Mountains areobtained on removing the objective content in the comments. Finally, only one subjective content or topic is retained for analysis. The semantics are divided into transportation, catering, accommodation, shopping, environmental health. 
Table 1. High-frequency characteristic words and word frequency statistics of the Five Great Mountains

\begin{tabular}{|c|c|c|c|c|c|c|c|c|}
\hline $\begin{array}{c}\text { Serial } \\
\text { number }\end{array}$ & Item & $\begin{array}{c}\text { Word } \\
\text { frequen } \\
\text { cy }\end{array}$ & $\begin{array}{c}\text { Serial } \\
\text { number }\end{array}$ & Item & $\begin{array}{c}\text { Word } \\
\text { freque } \\
\text { ncy }\end{array}$ & $\begin{array}{c}\text { Serial } \\
\text { number }\end{array}$ & Item & $\begin{array}{c}\text { Word } \\
\text { freque } \\
\text { ncy }\end{array}$ \\
\hline 1 & $\begin{array}{c}\text { 泰山(Mount } \\
\text { Thai) }\end{array}$ & 8096 & 16 & 晚上(Night) & 4556 & 31 & $\begin{array}{c}\text { 体力(physical } \\
\text { strength) }\end{array}$ & 3667 \\
\hline 2 & 日出(Sunrise) & 7199 & 17 & $\begin{array}{c}\text { 索道 } \\
\text { (Ropeway) }\end{array}$ & 4458 & 32 & $\begin{array}{c}\text { 便宜 } \\
\text { (Cheap) }\end{array}$ & 3622 \\
\hline 3 & $\begin{array}{c}\text { 华山(Mount } \\
\text { Hua) }\end{array}$ & 6788 & 18 & 风光(Scenery) & 4416 & 33 & 到达(Arrival) & 3619 \\
\hline 4 & $\begin{array}{c}\text { 嵩山(Mount } \\
\text { Song) }\end{array}$ & 6542 & 19 & $\begin{array}{c}\text { 景区(Scenic } \\
\text { area) }\end{array}$ & 4330 & 34 & 价格(Price) & 3512 \\
\hline 5 & $\begin{array}{l}\text { 衡山(Mount } \\
\text { Heng in } \\
\text { Hunan) }\end{array}$ & 6511 & 20 & 排队(Queuing) & 4309 & 35 & $\begin{array}{l}\text { 很美(Very } \\
\text { beautiful) }\end{array}$ & 3501 \\
\hline 6 & $\begin{array}{c}\text { 恒山(Mount } \\
\text { Heng in } \\
\text { Shanxi) }\end{array}$ & 6231 & 21 & 景色(Sight) & 4308 & 36 & $\begin{array}{l}\text { 夜爬(Night } \\
\text { climb) }\end{array}$ & 3484 \\
\hline 7 & $\begin{array}{c}\text { 壮丽 } \\
\text { (Magnificent) }\end{array}$ & 5892 & 22 & $\begin{array}{c}\text { 建议 } \\
\text { (Suggestions) }\end{array}$ & 4282 & 37 & 天气(Weather) & 3473 \\
\hline 8 & 绝壁(Cliff) & 5819 & 23 & $\begin{array}{l}\text { 登山(Mountain } \\
\quad \text { climbing) }\end{array}$ & 4200 & 38 & 步行(Walking) & 3352 \\
\hline 9 & $\begin{array}{c}\text { 五岳(The Five } \\
\text { Great } \\
\text { Mountains) }\end{array}$ & 5644 & 24 & 文化(Culture) & 4143 & 39 & 网上(Online) & 3330 \\
\hline 10 & 爬山(Climb) & 5398 & 25 & 俊美(Pretty) & 3941 & 40 & 休息(Rest) & 3299 \\
\hline 11 & $\begin{array}{c}\text { 风景 } \\
\text { (Landscape) }\end{array}$ & 5089 & 26 & $\begin{array}{c}\text { 气势 } \\
\text { (Momentum) }\end{array}$ & 3915 & 41 & $\begin{array}{l}\text { 很累(Very } \\
\text { tired) }\end{array}$ & 3259 \\
\hline 12 & 险峻(Steep) & 4836 & 27 & 感觉(Feeling) & 3877 & 42 & $\begin{array}{c}\text { 景点 } \\
\text { (Attractions) }\end{array}$ & 3246 \\
\hline 13 & $\begin{array}{l}\text { 山上(On the } \\
\text { mountain) }\end{array}$ & 4734 & 28 & $\begin{array}{c}\text { 缆车(Cable } \\
\text { car) }\end{array}$ & 3807 & 43 & 大巴(Bus) & 3231 \\
\hline 14 & 值得(Worth) & 4725 & 29 & 时间(Time) & 3783 & 44 & $\begin{array}{c}\text { 取票(Taking } \\
\text { tickets) }\end{array}$ & 3222 \\
\hline 15 & $\begin{array}{c}\text { 特色 } \\
\text { (Features) }\end{array}$ & 4687 & 30 & 门票(Tickets) & 3749 & 45 & 攻略(Guide) & 3198 \\
\hline
\end{tabular}

After drawing the word cloud, the text is semantically classified separately, which is based. After calculating the initial data of visitor satisfaction, this paper uses index weights to reflect the different roles played by each evaluation index in the overall review. At present, the 
methods for determining weights are mainly divided into two categories. One is the qualitative weighting method, which includes the fuzzy comprehensive evaluation method, analytic hierarchy process, etc. The other is the quantitative weighting method, including entropy weight method, principal component analysis method, regression analysis and so on. The entropy weight method is mainly used in this paper to determine the index weight, which is a method to determine the objective weight according to the index variability. The entropy weight method has strong objectivity and is fully applied to various types of original data where weights need to be determined. The evaluation standard of the entropy weight method is that if the entropy value of a certain evaluation index is smaller, it means that the index change value is larger. The more information is provided, the greater effect the evaluation has and the greater the weight is. When the entropy value is large, the information it provides is reversed [17]. The process of calculating weights by entropy weight method is as follows.

(1) Standardize the initial values of 9 evaluation indicators of the Five Great Mountains.

Let $\operatorname{\alpha ij}(i=1,2, \ldots, m ; j=1,2, \ldots, n)$ be the satisfaction value of the $j$-th index in the $i$-th evaluation object. The paper has 5 evaluation objects (The value range of $m$ is $1-5$ ) and the initial tourist satisfaction matrix A composed of 9 evaluation indicators (the value range of $n$ is 1-9), then $A$ is:

$$
\mathbf{A}=\left(\begin{array}{ccc}
a_{11} & \cdots & a_{\mathrm{m} 1} \\
\vdots & \ddots & \vdots \\
a_{1 \mathrm{n}} & \cdots & a_{\mathrm{mn}}
\end{array}\right)
$$

Formula 1. Tourist Satisfaction Matrix

Normalizing the values in the A matrix to obtain $\alpha^{\prime}$, then a new matrix A' is generated.

$$
A^{\prime}=\left(\begin{array}{ccc}
a_{11}^{\prime} & \cdots & a_{m 1}^{\prime} \\
\vdots & \ddots & \vdots \\
a_{1 n}^{\prime} & \cdots & a_{m n}^{\prime}
\end{array}\right)
$$

Formula 2. Standardized Tourist Satisfaction Matrix

Among them, the standardized formula is as follows.

$$
a_{i j}^{\prime}=a_{i j}-\min \alpha_{i j} / \max a_{i j}-\min a_{i j}
$$

Formula 3. Standardized Formula

$$
a^{\prime}{ }_{i j}=\max a_{i j}-a_{i j} / \max _{i j}-\min \alpha_{i j}
$$

Formula 4. Standardized Formula 
(2) Calculate the information entropy of each indicator.

$$
\mathbf{H}_{\mathbf{j}}=-\mathrm{k} \sum_{\mathrm{i}=1}^{\mathrm{m}} \text { pijInpij }
$$

Formula 5. Information Entropy

In the formula, $\mathrm{k}=1 / \mathrm{Inm}, \mathrm{P}_{\mathrm{ij}}=\alpha^{\prime} / \sum_{i=1}^{m} \alpha^{\prime}{ }^{\mathrm{ij}}$

Formula 6. Information Entropy

(3) Determine the weight Wj of each indicator.

$$
\mathrm{W}_{\mathrm{j}}=1-\mathrm{H}_{\mathrm{j}} / \sum_{\mathrm{i}=1}^{\mathrm{n}}\left(1-\mathrm{H}_{\mathrm{j}}\right)
$$

Formula 7. Index Weight

According to the above calculation results, the weights of 9 indicators (Table 2) and the satisfaction scores of the 9 indicators of the Five Great Mountains (Table 3) can be obtained. This paper then uses the weighted sum method to calculate the total satisfaction of tourists. The formula is as follows.

$$
\mathrm{E}_{\mathrm{i}}=\sum_{\mathrm{i}=1}^{9} \alpha^{\prime}{ }_{\mathrm{ij}} * \mathrm{~W}_{\mathrm{j}}
$$

\section{Formula 8. Tourist Satisfaction Formula}

The larger the Ei value is, the higher the tourist satisfaction is. The calculation result is shown in Table 3. Under a certain item, the closer the value is to 1 , the higher the tourist satisfaction of the indicator is, while the closer the value is to 0 , the lower the tourist satisfaction is.

Table 2. Evaluation Index System of Tourist Satisfaction in the Five Great Mountains

\begin{tabular}{|c|c|c|}
\hline Content & Index & Evaluation weight \\
\hline \multirow{4}{*}{$\begin{array}{c}\text { Total tourist satisfaction in the } \\
\text { Five Great Mountains }\end{array}$} & Transportation (0.08999) & \multirow{2}{*}{ Positive (1.0) } \\
\cline { 2 - 2 } & Catering (0.08947) & \\
\cline { 2 - 2 } & Accommodation (0.13081) & \multirow{2}{*}{ Neutral (0.5) } \\
\cline { 2 - 2 } & $\begin{array}{c}\text { Environmental health } \\
(0.15062)\end{array}$ & \\
\cline { 2 - 3 } & &
\end{tabular}




\begin{tabular}{|l|c|c|}
\hline \multirow{4}{*}{} & Landscape features (0.19161) & Negative (0.1) \\
\cline { 2 - 3 } & Cultural characteristics \\
$(0.07940)$ & Infrastructure (0.08697) \\
\cline { 2 - 3 } & Service management (0.10075) & \\
\cline { 2 - 4 } & & \\
\hline
\end{tabular}

Table 3. Tourist Satisfaction Ranking and Calculation Results of the Five Great Mountains

\begin{tabular}{|c|c|c|c|c|c|}
\hline Index & Mount Thai & Mount Hua & $\begin{array}{l}\text { Mount Heng } \\
\text { in Hunan }\end{array}$ & $\begin{array}{l}\text { Mount Heng } \\
\text { in Shanxi }\end{array}$ & Mount Song \\
\hline \multirow[t]{2}{*}{ Transportation } & 1 & 4 & 5 & 2 & 3 \\
\hline & 1.000 & 0.387 & 0.000 & 0.772 & 0.542 \\
\hline \multirow[t]{2}{*}{ Catering } & 1 & 4 & 5 & 2 & 3 \\
\hline & 1.000 & 0.382 & 0.000 & 0.744 & 0.564 \\
\hline \multirow[t]{2}{*}{ Accommodation } & 1 & 3 & 5 & 4 & 2 \\
\hline & 1.000 & 0.484 & 0.000 & 0.120 & 0.634 \\
\hline \multirow[t]{2}{*}{ Shopping } & 1 & 5 & 4 & 3 & 2 \\
\hline & 1.000 & 0.000 & 0.531 & 0.634 & 0.662 \\
\hline \multirow[t]{2}{*}{ Environmental health } & 5 & 2 & 1 & 3 & 4 \\
\hline & 0.000 & 0.602 & 1.000 & 0.338 & 0.080 \\
\hline \multirow[t]{2}{*}{ Landscape features } & 2 & 3 & 4 & 5 & 1 \\
\hline & 0.503 & 0.123 & 0.081 & 0.000 & 1.000 \\
\hline \multirow[t]{2}{*}{ Cultural characteristics } & 4 & 3 & 5 & 2 & 1 \\
\hline & 0.519 & 0.707 & 0.000 & 0.757 & 1.000 \\
\hline \multirow[t]{2}{*}{ Infrastructure } & 1 & 4 & 5 & 3 & 2 \\
\hline & 1.000 & 0.414 & 0.000 & 0.574 & 0.698 \\
\hline \multirow[t]{2}{*}{ Service management } & 5 & 1 & 3 & 2 & 4 \\
\hline & 0.00 & 1.000 & 0.568 & 0.852 & 0.274 \\
\hline \multirow[t]{2}{*}{ Total tourist satisfaction } & 1 & 3 & 4 & 5 & 2 \\
\hline & 0.614 & 0.449 & 0.439 & 0.266 & 0.606 \\
\hline
\end{tabular}

Data source: Author

\section{Tourist Satisfaction Analysis}

\subsection{Satisfaction analysis of single scenic spot}

Based on the data analysis results of Chapter 2 (ie, Table 3), the satisfaction of the Five Great Mountains is ranked. The Mount Thai, which is the "First of the Five Great Mountains and the First Mountain in the World", has obtained the highest ranking of multiple indicators and total 
tourist satisfaction. However, the scores of the two indicators of environmental health and service management are at the bottom, such as "vacation", "congestion", "high price", and "extra charge". Some scenic spots have irregular behaviors of extra charges after entering the mountain. The management of the surrounding taxis is not perfect and there is a phenomenon of slaughtering customers. This shows that the environmental health problems caused by the flow of people and the difficulty in providing quality services in scenic spots still exist. This shows that the environmental sanitation problem caused by high flow of visitor traffic and the problem that scenic spots cannot provide high-quality services still exist. In order to consolidate the top position of the Five Great Mountains, it will be important to increase manpower and material resources to improve the service management quality of scenic spots and ensure the sanitary environment on the mountains.

The Mount Song, which ranks second in overall satisfaction, is an important birthplace of Chinese civilization. As the World Geopark, it has undoubtedly been praised by the vast number of travelers in terms of landscape features and cultural characteristics, which are both in the first position of the index. From text analysis, this is mainly due to the combination of the Mount Song's own strong cultural atmosphere and the magnificent mountain scenery. In addition, the Shaolin martial arts bring a more profound tourism experience to tourists. In terms of other indicators, the Mount Song ranks in the middle. Like the Mount Thai, it has certain deficiencies in environmental health and service management. For example, "fewer toilets", "rough rest areas" and "fewer garbage bins" need to be further improved.

The Mount Hua, ranking the third in total satisfaction, is the most challenging mountain of Chinese civilization. Data analysis of the collected text shows that the Mount Hua is in the middle of many indicators, but it has won the first place in service management. However, in the shopping experience, it is at the end of the ranking. According to the content of reviews, when tourists lack food and water supplement in high-altitude areas, some tourists encounter the situation that the price of goods is raised at the transaction place, which will inevitably cause great dissatisfaction among tourists. The management department should pay attention to the price management of shopping in scenic spots. Under the premise of fully considering the difficulty of transportation of goods at high altitudes, it should appropriately grant certain subsidies and formulate uniform price standards. What is more, it should implement price supervision and dynamic inspections. If they find that the price is raised at the transaction place, the legitimate rights and interests of tourists should be protected timely.

As a national nature reserve, the Mount Heng in Hunan ranks fourth in total satisfaction and ranks first in the Five Great Mountains in terms of environmental health, indicating that the scenic area attaches great importance to management and invests a lot of manpower and material resources. However, the satisfaction in transportation, catering and accommodation is not high. The complaints are mainly reflected in the rapid speed of mountain sightseeing cars and the rugged mountain roads causing tourists to experience motion sickness, etc. Some tourists have proposed that the bus lanes lack guardrails. Therefore, to a certain extent, it causes panic for tourists. In terms of catering, the poor taste of the meals served in the affiliated restaurants of the scenic area does not reflect the characteristics of Hunan cuisine. With regard to accommodation, the evaluation shows that the environment is shabby and expensive. In addition, the price of burning incense in newly-developed temples is too high, so it is necessary for the scenic spot to strengthen the management.

As the only 4A-level scenic spot in the Five Great Mountains, the Mount Heng in Shanxi is the last in the ranking of total tourist satisfaction. The main problem is that it has a relatively low development level. For example, the road to the mountaintop is not long and the time to climb the mountain is short. Tourists who have visited the other four mountains do not rate the 
Mount Heng in Shanxi very high caused by the large difference. In addition, the Mount Heng in Shanxi is located in Hunyuan county, Datong city, Shanxi province. The long round-trip drive also leads to dissatisfaction of some tourists. However, in addition to the landscape features of the Mount Heng in Shanxi, the ranking of other indicators is in the middle, indicating that the local scenic spots are well managed and there is something worth learning.

\subsection{Analysis of factors influencing tourist satisfaction}

In the index system for tourist satisfaction evaluation of the Five Great Mountains Table 2), it can be seen from the analysis of index weights that the accommodation, environmental health, landscape features and service management of the scenic spot reached $57 \%$ of the total. Among them, the biggest impact on tourists is landscape features (0.19161), followed by environmental health (0.15062) and accommodation (0.13081). Service management (0.10075) and transportation (0.08999) rank fourth and fifth respectively, which also have a great impact on tourist satisfaction with a scenic spot. With the gradual improvement of people's living standards, their requirements for the quality of scenic spots are also constantly improving. As a result, it is important to enhance these five aspects which are beneficial to tourists' perceived quality.

\section{Discussion and Suggestions}

Based on the above analysis, this paper proposes the following recommendations and suggestions.

1. Strengthen the information construction of scenic spots. The Internet has brought about historic changes and smart tourism has opened up new ways for scenic spots to go up in service and management. Therefore, in order to improve the competitiveness of scenic spots, it is important to increase investment in information construction and improve the intelligent service. As a result, big data collection and analysis should be fully used to regularly collect and analyze feedback information from tourists. In this way, the problems in scenic spots can be rectified specifically by paying attention to the opinions and suggestions of tourists. it could improve the shortcomings of software and hardware in services, improve infrastructure and transportation facilities, strengthen traffic guidance for tourists in peak seasons, and strengthen sanitation supervision and inspection. Thus, a safe, comfortable and orderly tourism environment for tourists can be created [18]. In addition, it could achieve a win-win situation between economic and social benefits by improving tourists' satisfaction in all aspects and improving management benefits of scenic spots [19].

2. Strengthen the construction of the tourism talent team. Tourism service is a window for a city to demonstrate its civilization, while tourism practitioners are the most direct propagators and bearers of a city's civilization. Therefore, tourism functional departments and scenic area management should attach great importance to training and continuously improving the professional skills and professional ethics of tourism practitioners. They should be aimed at new problems, new situations and new requirements in service. In this situation, the training work should be classified, planned and carried out in a targeted way to indeed improve the actual effect of the training. Training cannot be accomplished overnight and the improvement of service quality and tourist satisfaction is always on the way [20].

3. Highlight the characteristics and broaden the channels of tourism projects. The scenic spots in the Five Great Mountains should actively develop new tourism products according to their characteristics and increase the added value of tourism projects. Highlighting features is an effective way to attract tourists and increase the added value of tourism. There are three ways 
of emphasizing features of scenic spots. The first is to develop dishes with local characteristics to satisfy the tourists 'experience and pursuit of local cuisine. At the same time, strengthen the supervision and inspection of the prices in the scenic spots to protect the legitimate rights and interests of consumers. The second is to create local-style homestays and seek to combine with poverty alleviation projects effectively. For example, the local government can give certain policy and financial support to formulate homestay service standards, strengthen training homestay service personnel, strengthen health supervision and inspection and use self-media or other tourist-like ways to guide tourists to experience, so as to achieve a win-win situation by combining poverty alleviation and characteristic homestay project. Thirdly, developing tourist souvenirs with unique local characteristics and cultural characteristics and avoiding similarities in the development of new tourism products. In this way, special products in the Five Great Mountains can be created, so as to enrich the tourist souvenir market and satisfy tourists' shopping demand, as well as protecting intellectual property rights.

4. Promote the culture of the Chinese nation and tell stories of the Five Great Mountains. The Five Great Mountains are the carrier of inheriting and carrying forward the Chinese culture. Every mountain with a long history and culture is an important part of Chinese civilization. Its spirit and cultural connotation have been circulating for thousands of years. Therefore, telling a good story of the Five Great Mountains, inheriting the essence of the millennium culture and advancing with the times to give the new era connotation are not only the responsibility but also the obligation of every tourist practitioner in the scenic spot. Every tourist practitioner in the scenic spot must fulfill its obligations with good professional qualities and professional ethics, in order to become a powerful promoter of improving the cultural self-confidence of the Chinese nation.

5. Improve the reception capacity of tourists in the peak period of scenic spots. Most tourists will choose to go to the scenic area for a holiday. In order to deal with the huge passenger flow, in addition to receiving tourists properly in the reception area of the scenic spots, they must also prepare for emergency situations and safety accidents. In the statistical text, some tourists complained that there are too many people in the holiday, which is too crowded and difficult to walk. There are also comments that poor security facilities could not guarantee the safety of a large number of tourists. This has more or less reduced tourists' satisfaction with the scenic area. Therefore, scenic spots should make good use of modern technology. For example, they can analyze the tourist capacity and environmental carrying capacity of scenic spots to ensure the safety and order of scenic spots. In addition, it is important to reasonably receive tourists and improve the regulatory level and dynamic prediction ability of scenic spots, so as to guide the flow of tourists scientifically.

\section{Conclusions and Limitations}

Based on the content of the review, this paper uses OTA review data to build a tourist satisfaction evaluation index system to evaluate the tourist satisfaction of the Five Great Mountains. The R language and other software are also used to conduct a text analysis of the tourist reviews. Through comparative analysis, we got the following conclusions. (1) Through horizontal comparison, it can be found that the ranking of tourist satisfaction among the Five Great Mountains in order is from the Mount Thai, the Mount Song, the Mount Hua, the Mount Heng in Hunan to the Mount Heng in Shanxi. In addition to the factors of the scenic spot itself, tourist satisfaction is also affected by local policies and geographical locations. (2) Based on the factors, the analysis text shows that the focus of tourism is on the index of landscape characteristics, followed by great attention to the environmental protection of scenic spots. 
However, the data sample is small in the aspects of catering and shopping in the scenic area. According to the classification results of emotions, these two indicators have low scores with mostly negative emotions. In addition, the local government should strengthen the "four constructions and one promotion" of the Five Great Mountains, which is strengthening cultural characteristic construction, strengthening talent team construction, strengthening infrastructure construction, strengthening informatization construction and promoting the scenic area 's smart tourism [21]. It is also important to consolidate the leading position of the Five Great Mountains in the province and vigorously promote the development of the tourism economy of the province, so as to achieve the purpose of promoting the economic development of the province.

This paper has made some contributions in related research fields. As for the research objects, this study uses the method of quantifying the satisfaction of scenic spots to compare and study the satisfaction of tourists in the Five Great Mountains, which have high tourist reviews on the OTA website. It is of certain significance for the tourism industry of China to achieve differentiated development through mutual comparison and reference. In terms of research methods, the text analysis, social network analysis and the entropy weight method are used in this paper to compare different scenic spots. A multi-dimensional quantitative comparative analysis of satisfaction is of certain significance for discovering the advantages and disadvantages of different tourist attractions to achieve precise development. In addition, in the construction of evaluation indicators for scenic spots, this paper combines existing research results and the word frequency characteristics of the evaluation of the Five Great Mountains, dividing the scenic spot into 9 sub-evaluation dimensions, which enrich the related research on scenic spot evaluation to a certain extent.

However, there are still some limitations in this study. Firstly, in terms of data samples, the data collected from three travel platforms needs to be further expanded. Since the user information of tourists cannot be identified, it is difficult to determine the representativeness of the samples, so that it is impossible to determine the satisfaction of tourists from a scientific perspective. Secondly, the paper does not categorize the content of the reviews in time, but only calculates the content and semantics according to the weight score during the calculation. For example, some tourists made suggestions in 2015 and the scenic spot management department may have rectified the problem in 2016, so that some scenic spot projects cannot obtain an absolute objective score when doing the calculation, which affects the tourist satisfaction ranking of the scenic spot. Finally, with regard to research methods, this paper mainly uses text analysis, followed by semantic classification and sentiment analysis to screen the text. However, this method can only passively obtain the satisfaction and dissatisfaction of tourists expressed in scenic spots. In the future, we can conduct on-site investigations and social surveys on key low-score project indicators after data analysis. In this way, we can study how to improve low-score projects to contribute to enhancing the satisfaction of scenic spots.

\section{References}

[1] Gov.cn., "Boosting Tourism Development With Informatization Construction-Interpretation Of The "Thirteenth Five-Year Plan For National Tourism Informatization," 2017. [online] Available at: http://www.gov.cn/ [Accessed 6 May 2020].

[2] Zuo, D.J., “The 13th Five-Year Plan for National Tourism Informationization,” China Tourism News, 2017. Article (CrossRef Link).

[3] Radojevic T. and Stansic N., "Ensuring positive feedback: factors that influence customer satisfaction in the contemporary hospitality industry," Tourism management, Vol. 51, No. 1, pp. 13-21, 2015. Article (CrossRef Link). 
[4] Zhao P.Y., Cui Q., Zhang H. et al., “A Tourist Satisfaction Researchonthe Tourism Destination of the World Heritage in Shanxi Based on the Network Comments," Shanxi Normal University (Natural Science Edition), Vol. 30, No. 3, pp. 64-69, 2016. Article (CrossRef Link).

[5] Li L.M., Wang X.F., Liu Y. et al., "The Evaluation Model Construction of Tourist Satisfaction in Xi'an Key Scenic,” Value engineering, Vol. 31, No. 25, pp. 285-287, 2012. Article (CrossRef Link).

[6] Cardozo R. N., “An experimental study of customer effort expectation and satisfaction,” Marketing Research, Vol. 2, No. 3, pp. 244-249, 1965. Article (CrossRef Link).

[7] Pizam A., "Tourism 's impacts: the social costs to the destination community as perceived by its residents,” Travel Research, Vol. 16, No. 4, pp. 8-12, 1978. Article (CrossRef Link).

[8] Pizam A., Neumann Y., Reichel A., "Dimensions of tourist satisfaction with a destination area," Annals of Tourism Research, Vol. 5, No. 3, pp. 314-322, 1978. Article (CrossRef Link).

[9] Zhang G. X., Jiang Y. L., "Study on overseas communication strategy of Taishan culture under the background of tourism market demand,” China Marketing, Vol. 8, pp.127-128. 2021. Article (CrossRef Link).

[10] Cui Y., "Influence index and promotion strategy of tourists' satisfaction in mountain scenic spots," Research on Development, Vol. 2, pp. 71-77, 2018. Article (CrossRef Link).

[11] Shen Y. and Su Q., "Research on the satisfaction evaluation of tourist items in ethnic villages: Taking Longji Scenic Spot in Longsheng County, Guilin, Guangxi as an example,” Chongqing University of Science and Technology (Social Science Edition), Vol. 5, No. 1, pp. 101-102, 2009. Article (CrossRef Link).

[12] Liu N. and Wu Z.J., "A study on the current situation of tourism satisfaction of Longji terraced scenic spots in Guilin, Guangxi,” Popular Science, Vol. 17, No. 5, pp. 162-164, 2015. Article (CrossRef Link).

[13] Xu Y.H., You X.B., Wang Y.N., "Evaluation of tourist satisfaction based on ROSTCM method: a case study of five domestic terrace scenic spot,” Tourism Forum, Vol. 11, No. 5, pp. 23-24, 2018. Article (CrossRef Link).

[14] Gao J., "A Case Study of Slender West Lake in Yangzhou about Marking Strategy : Based on Bigdata Based Content Analysis,” Jiangsu Business Review, Vol. 8, No. 1, pp. 34-41, 2018. Article (CrossRef Link).

[15] He Y. and Yang X.X., “Application and comment of content analysis method in tourism research in China," Southwest Yongye University, Vol. 10, No. 4, pp. 6-12, 2012. Article (CrossRef Link).

[16] Sun Y., "A Study on the Satisfaction of Outbound Tourists Based on Data Mining on the Internet Social Platform,” Shanghai: Shanghai Normal University, 2015. Article (CrossRef Link).

[17] Huo D.L., Liu L.F., "Weight of Social RiskEarly-Warning Index of Beijing Winter Olympics Based on Entropy Weight Method,” Shenyang Institute of Physical Education, Vol. 38, No. 5, pp. 47-55, 2019. Article (CrossRef Link).

[18] Chen X.X., "Thoughts on improving the quality of tourism industry," Shandong Academy of Agricultural Management Cadres, Vol. 2, No. 1, pp. 84-85, 2006. Article (CrossRef Link).

[19] Zhu L., "On Scenic Spot Ticket Price Managementfrom the Perspective of "DoubleFailure”, Journal of Zhejiang Wanli University, Vol. 27, No. 2, pp. 11-15, 2014. Article (CrossRef Link).

[20] Sun Y., "Analysis and suggestion on the status quo of the use and management of college funds," Contemporary Accounting, Vol. 3, pp. 66-67, 2016. Article (CrossRef Link).

[21] Yang Q.R., "Analysis on the construction of rural public cultural service system in minority areas," Caizhi, Vol. 1, pp. 267-268, 2017. Article (CrossRef Link). 


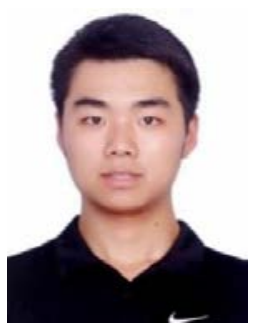

Hanwen Guo received the B.A. degree in Finance from University of Science and Technology Beijing, China, in 2015. He obtained a master's degree in agronomy from Guangxi University in 2018 and a doctor's degree in Business Administration from Kyonggi University in Korea in 2021. He is currently a lecturer in the Department of marketing, Business School, Guangxi University of Nationalities. He is interested in International Trade and Economics, Tourism Marketing, E-business, etc.

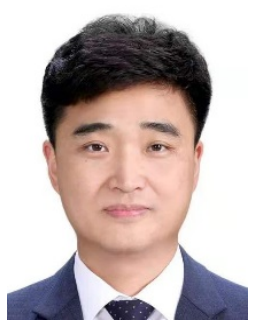

Ziyang Liu received the B.A. degree in Management from the Institute of Army Staff Officer of the PLA, China, in 2006, M.A. degree and Ph.D. degree in Management from Kyonggi University, Korea, in 2010 and 2013, respectively. He is currently a Professor in Global Business at Kyonggi University. He is interested in Quality Management, Management Information Systems, International economics, E-customization etc.

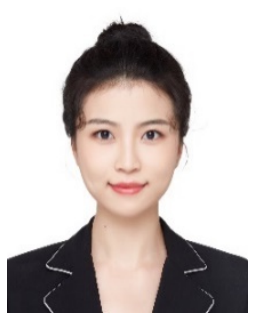

Zeyu Jiao received the double B.A. degree in English and International Economics and Trade from Shanxi University of Finance and Economics, China, in 2015. She received M.A. degree in Marketing from University of Exeter, UK, in 2017. She is currently working toward the Ph.D. degree in Global Business at Kyonggi University, Korea. Her research interests focus on Big Data, Knowledge Management and Customer behavior. 